\title{
Short Films and Their Festivals
}

\author{
By Patricia Thompson
}

Fall 1995 Issue of KINEMA

THE LAUNCHING of the Toronto Worldwide Short Film Festival in May brought about the realization that there are a respectable number of showcases for Canadian short films, and some completely devoted to the national product. Most of these festivals are juried with filmmakers competing for awards of cash or services. The Montréal International Short Film Festival was into its third year in April; The Toronto International Film Festival celebrated the 12th anniversary of its Perspective Canada program in September, while in Saskatchewan, the Yorkton Short Film and Video Festival was 31 years old in May and still kicking up its heels. Many more festivals show short films of a more specialized nature. The Ottawa International Animation Festival is staged every two years in Ottawa and our animators stand out there -- taking part in what must surely be one of our national sports categories! Hot Docs is organized at the start of each year in Toronto by the Canadian Independent Film Caucus of -- what else -- documentaries; the National Screen Institute in Edmonton turns the spotlight on distinctive, independent dramas from Canada and around the world in March, and the Canadian Student Film Festival, first organized in 1969, is a part of the Montreal World Film Festival during August.

The Toronto Worldwide Short Film Festival, the newcomer on the block, arrived with a tiny fanfare, and not exactly a rush of publicity. The writer attended three sessions, including the opening international program on a Thursday afternoon at 4 p.m. and there were a fair number of people in a small cinema. The program started 20 minutes late, and was introduced by a young man who announced that one film had not arrived from Australia. When a member of the audience enquired about a replacement, he was completely taken aback to think that someone who had paid an admission expected a substitute film. A couple of Canadian programs on Friday afternoon were fairly well attended, both started late again, but yielded some moderate successes. Rich Harkness' The Waiting Room (12 min), gives us a little comedy of two men, tortured by "muzak" in "the waiting room for hell," one of whom intends to beat the rap, and this was in direct contrast with another comedy, Elaine Dumont's Confidence pour confidence (10 min), all about loneliness with religious overtones.

Philip Barker's A Temporary Arrangement (12 min) was a mesmerizing re-arrangement of fractured images of family and friends seemingly walking and floating on a little country stream. John Fawcett's Scratch Ticket (10 min), a very short road movie with a infantile attitude and an alleged script consisting mainly of four-letter words, was introduced by the almost tongue-tied director. Christopher Hinton's Watching TV is an upsetting five minutes of animated bullets, bloodshed and mayhem as seen on the tube every day. In a longer piece by Denis Villeneuve REW F FWD (Rewind Fast Forward, $30 \mathrm{~min}$ ), a photographer who is visiting Jamaica has a car breakdown in a ghetto area. At first he's apprehensive but, during the days of waiting to have his car repaired, he comes to appreciate the people living and working around him. Other Canadian programs included a couple of films seen at the 1994 Atlantic Film Festival: Mi'kmaq Family (32 min) is a charming insight into the large Mi'kmaq "family" in Nova Scotia, which had a rousing first screening in Halifax with the director, Catherine Anne Martin, drumming and singing prior to the film. And then there was Vera Saar's marvellous Tick Flicks, 2 min of 35mm animation, with strange bulbous ticks illustrating various other hilarious "ticks" -- semanticks, artickulates, criticks -- you get the picture. And yet another popular re-run of the NFB and UK Channel 4 Oscar-winning Bob's Birthday (12 min), wonderfully animated by Allison and David Fine, depicting dentist Bob's quietly hilarious mid-life crisis on reaching his fortieth birthday.

Most of the short film festivals have survived for a number of years, with Yorkton as the shining example, but the newer ones will have a harder road with government culture cuts in funding, and sponsorship bushes being heavily beaten. The Montreal fest gathered momentum in its third year and had its 1996 "call for entries" form out in October. For 1995 it reported 7,000 people attended, an increase of 40 per cent over 1994. In its first year the Toronto fest reported "over 2,000 film enthusiasts attending," with the founder declaring: "Yes, there will be a festival in '96, and we do not think that financing grants will be difficult now that we have successfully completed our first year." We're watching... 


\section{Author Information}

Patricia THOMPSON (d. 1999) was Publisher and Editor of Film Canada Yearbook and Canadian Editor for the International Motion Picture Almanac and the International Television and Video Almanac (Quigley, NY). She was reviewing Canadian short films for several decades. 